\title{
Big Data GIS Analytics Towards Efficient Waste Management in Stockholm
}

\author{
Shahrokni, H.; van der Heijde, B.; Lazarevic, D.; Brandt, N. \\ Department of Sustainable Development, Environmental Science and Engineering, Industrial Ecology \\ Royal Institute of Technology \\ Stockholm, Sweden \\ Email: hosseins@kth.se
}

\begin{abstract}
This paper presents preliminary findings from a big data analysis and GIS to identify the efficiency of waste management and transportation in the City of Stockholm.

The aim of this paper is to identify inefficiencies in waste collection routes in the city of Stockholm, and to suggest potential improvements. Based on a large data set consisting of roughly half a million entries of waste fractions, weights, and locations, a series of new waste generation maps was developed. This was the outcome of an extensive data curation process, followed by batch geocoding of the curated entries. Thereafter, the maps were generated that describe what waste fraction comes from where and how it is collected. Finally, a preliminary analysis of the route efficiency was conducted. Maps of selected vehicle routes were constructed in detail and the efficiencies of the routes for the first half of July 2013 were assessed using the efficiency index (kg waste $/ \mathrm{km}$ ). It is concluded that substantial inefficiencies were revealed, and a number of intervention measures are discussed to increase the efficiency of waste management, including a shared waste collection vehicle fleet.
\end{abstract}

Index Terms-Big Data Analytics, GIS, Smart Cities, Transportation, Waste Management

\section{INTRODUCTION}

Rapid urbanization and population growth during times of limited resources is one of the greatest challenges we face. Currently, $50 \%$ of the world population live in cities and by 2050, this figure is predicted to reach $70 \%$ [1]. A parallel challenge is a changing and deteriorating environment, including the changing climate and rapid resource depletion [2]. To reverse these trends, policy-makers, organizations and citizens need to re-adapt their resource use. [3] propose that this can in part be counteracted by recent advancements in ICT. Thereby, ICT can become the enabler towards "a transition to a less material-intensive economy" [4]. Cities that use ICT as an enabler towards this transition are called Smart Cities.

On the concept of 'Smart Cities', Caragliu et al. [5] say: "We believe a city to be smart when investments in human and social capital and traditional (transport) and modern (ICT) communication infrastructure fuel sustainable economic growth and a high quality of life, with a wise management of natural resources, through participatory governance." The awareness of the potential values that this knowledge brings with it has spurred a rapid growth in the number of emerging smart cities [6], with large funding grants invested for related research and development.
For the City of Stockholm, traffic is the key barrier to meeting environmental goals [7]. There are smart city solutions that have already been implemented in this regard, such as congestion taxing [8]. As waste management is dependent on waste collection vehicles constantly moving around in the city, this is particularly a field that should be better understood, since despite congestion taxing and telecommuting measures, the waste needs to be collected. The challenges associated with waste transport and inner city traffic are the main concern of waste management companies. This applies particularly to companies that do not have a contract for a given geographic area, but instead need to collect from customers across the entire city. This issue becomes even more challenging since different customers have different preferences (time of collection, type of waste, etc.) [9].

It could be argued that the essence of the described concept of smart cities is data. Big data are redefining how research is made [10] and allows for a more specific understanding of the causalities that govern cities. As with most big data analyses first step in this process is to understand the current situation, analyse it, and then identify intervention measures, and if needed include predictions of waste generation in current operations [11].

The aim of this paper is to collect, curate, and analyze waste management collection data, to identify inefficiencies in waste management collection, and make recommendations on intervention measures. Because of difficulties with the data set, only a limited amount of data was used to investigate the vehicle route efficiency in this study, while recommendations have been made to increase the data quality requirements on the data .

\section{RELATED WORK}

This section provides a brief overview previous research related to waste collection and efficiency in the areas of a) cost efficient waste management, b) optimal route algorithms, and c) real-time data.

\section{A. Cost Efficient Waste Management}

Cost efficient waste management is concerned with defining factors that influence the cost of waste collection by evaluating cost efficiency. Hirsch [12] was among the first to investigate 
the correlation of factors relating to the service of waste collection (number of employees, characteristics of the collection areas, stop density etc.) and the cost per collected weight of waste. One of the largest obstacles for this study was the lack of accurate data. The main result in this paper is a regression model, which indicates the influence of various parameters (collection frequency and density, private vs. public collection companies, user charge vs. general revenue financing, and even curb vs. rear of the house waste collection) on collection cost.

Bosch et al. [13] attempted to define the cost efficiency for waste collection in 75 Catalonian municipalities. They used several strategies (Cobb-Douglas (logarithmic) regression, stochastic production frontier, data envelopment analysis (DEA) and free disposal hull) in order to form a model that predicts the cost, using the number of waste collection vehicles, number of non-administrative employees, collection frequency and collected fractions as inputs. The conclusion is that DEA is suited best for analysing cost efficiency, however other conclusions remain unclear because of the lack of data, as in the above-mentioned study. Dijkgraaf and Gradus [14] used comparable methods to deduct the efficiency of waste collection in the Netherlands. The aim of their study was to examine whether private collection is more efficient than public collection. They conclude that contracting out waste collection to private firms would increase the cost efficiency. However, fiscal regulations in the Netherlands hinder this transition.

Rogge and De Jaeger [15] used DEA to calculate the waste collection cost efficiency in the Flemish municipalities. In addition to the focus of preceding studies, they also studied related demographic information, such as age composition of the population, political preferences, income etc. De Jaeger et al. [16] had previously used the same dataset to investigate the influence of policies (such as weekly instead of bi-weekly collections, municipal joint ventures, and policies that aim to reduce waste generation). Another application of DEA on Spanish waste collection was conducted by GarcíaSanchez [17].

\section{B. Optimal Route Algorithm}

The second category of studies focuses on minimizing transportation of waste collection through optimal routing algorithms. For example Kim et al [18] use two methods to calculate an optimal set of routes, the first being Solomon's insertion algorithm, the second being a clustering algorithm. Their aim was to minimize the driven distance, as well as to balance the workload. At the same time, the constraint of legally prescribed lunch breaks (so called time-window problem) had to be satisfied. McLeod and Cherrett [19] suggested a route optimization for three areas and connected waste companies in North Hampshire (UK). By applying simple rerouting, sharing of routes between the 3 areas and adding vehicle depots at the waste disposal sites, they estimated annual savings as large as $10,000 \mathrm{~km}$ for the studied routes (this covers one fifth of all routes in North Hampshire). Another study performed by Wy, Kim and Kim [20] studied a routing algorithm for waste collection using roll-on/roll-off containers, again while factoring in the time windows.

Buhrkal, Larsen and Ropke [21] were one of the first to suggest the environmental importance of optimizing waste collection itineraries. They utilized an adaptive large neighborhood search algorithm, and a clustering method and their scope was residential waste collection. Depending on the computation time, using the actual collection points and lunch time windows, the savings amounted to $13 \%$ average. With larger time windows and better starting conditions, heuristics with a distance reduction of up to $45 \%$ could be achieved.

\section{Real-time Data}

In 2011, Faccio, Persona and Zanin [22] investigated the feasibility of communication between bins, collection vehicles and a central operator. The waste bins can be fitted with a volumetric sensor, RFID and GPRS communication and can send information about their status. Using this real-time data, routes can be optimized in order to make optimal use of the vehicle's cargo space. Waste containers that still have not reached a certain threshold to be emptied are skipped by, saving valuable travel time and distance. Also of importance, fewer waste collection vehicles were needed. A key finding was that the economic feasibility of providing a sensor network to support waste management in this case, was estimated to a payback period of roughly three years.

\section{Methodology}

The process to identify patterns in the spatial distribution of waste generation and inefficiencies in collection of waste is described here. This begins with an overview of the dataset's characteristics. The dataset's addresses were curated, geocoded and mapped to corresponding zip codes. Finally, the weight of generated waste aggregated by zip code was computed and visualised. In addition, to demonstrate inefficiencies in the waste management logistics, selected vehicle routes were mapped and an efficiency index was computed.

\section{A. Dataset}

The given waste dataset consisted of roughly 500,000 entries with following attributes:

- the amount and unit of waste,

- the type of waste,

- the collection address, time and date,

- the final waste disposal site,

- the waste management company and

- the waste management vehicle licence number.

Since there were 30 waste management companies entering data independently with little quality control and rules on set on the incoming data, the data curating process became quite resource-intensive. The weight and volume metrics were converted to kilograms. The raw data included 80 different fractions (mostly due to varying fraction naming for different companies), that were mapped to four general fractions (bulky, electronic, fat and mixed waste). 


\section{B. Geocoding}

1) Initial attempt: In a first run, all addresses $(15,066$ unique) were processed using the Google Maps API. This tool took a series of addresses as an input, and produced a list of locational coordinates.

However, given the bad quality of the address lines only approximately 10,000 addresses could be geocoded (65\%). The most frequent problem was that addresses did not always belong to the municipality of Stockholm. Since the entries lacked municipality, the addresses were geocoded across all of Sweden and even in other countries; in reality, all of those entries belonged to the municipality of Stockholm or surrounding municipalities. Given the resources available, the best course of action was therefore to set the municipality to Stockholm, and exclude the other entries for this study.

Other frequent errors were spelling mistakes, additions of letters to the house numbers, arrays of house numbers, addition of the neighborhood by some companies, and unrecognizable abbreviations.

2) Curating and adding zip codes: Curating and correcting 5000 addresses one by one would be highly resource-intensive, therefore the occurrence of the unrecognizable addresses was checked. Of the 500,000 data entries, 140,000 had an unrecognized address. A few unrecognized addresses occurred in up to 1000 waste entries each. The 60 addresses with the highest number of entries were manually corrected, leading to an additional 10,000 waste data entries becoming valid. By adding these addresses to the database, additional coordinates could be corrected (e.g. by assuming that addresses in the same street have approximately the same coordinates), increasing the curated set to $73 \%$ of the original set.

The zip codes were added added by intersecting the resulting coordinate layer with a zip code shapefile layer in QGIS.

\section{Aggregation of Waste Data}

The primary analysis was an aggregation of waste per zip code, both for all types of waste together and per waste fraction. The resulting table was used to make a waste generation map for the City of Stockholm. In order to identify which companies operate in which part of the city, the data was also spatially aggregated per company and per treatment facility.

The maps indicate where there are a higher number of active waste management companies, and thereby possible inefficiencies, as more waste management companies within the same zip code indicate more waste collection vehicles for the same area and fraction.

\section{Choropleth Mapping}

To generate waste maps, the data set was normalized by the population of each zip code. This does result in maps that indicate higher waste densities in the periphery of Stockholm ()lower population density), where several large industries are located. However, the city center still generates the highest amount of waste both in absolute and relative numbers.

For best visualisation results, the Jenks natural intervals algorithm was chosen. This method defines the breaks between the different classes such that the variation of data within the separate classes is small, while making sure that the classes are far enough apart [23].

\section{E. Mapping of Waste vehicle Routes}

In order to map the routes of each vehicle, the data was filtered by company, date, and license number. Three larger companies were selected that had provided the highest quality entries of time and location. The selected time period for the comparison of these companies was the first two weeks of July 2013. The three companies that were studied are named A, B and $\mathrm{C}$, and they all have a high number of events during that time period.

To calculate the route length and times between the different stops a batch routing tool ${ }^{1}$ was used. This is a PHP-plugin that requests the routes between a sequence of collection stops from the Google Maps API. Even though the actual route between two collection points cannot be derived from the data, the Google route is a sufficient approximation of the actual path taken by the vehicle for the purpose of this study.

The efficiency of the itinerary can be quantified using the ratio of transported waste during a trip divided by the travelled distance:

$$
\beta=\frac{m_{\text {waste }}}{d_{\text {route }}}=\frac{\text { amount of waste }}{\text { distance travelled }}
$$

This indicator should not be interpreted as the only measure of efficiency. Possible factors that influence this indicator are discussed in the results section.

\section{RESULTS}

\section{A. Geocoding}

The geocoded addresses are concentrated in and around the center of Stockholm, with a few (approximately 100) outliers towards the towns that surround the city. While representing a smaller part of the dataset, the incorrect observations were removed from the data set.

\section{B. Choropleth Maps}

After the aggregation, the waste data could be visualized on various categories. The first map illustrates the total amount of waste per capita and zip code (see Figure 1). In this map, the largest amounts of waste per citizen come from the city center: Östermalm, Norrmalm, Kungsholmen, Gamla Stan, Södermalm and Djurgården. Further, extremes in waste generation are found around Solna and Kista, and in some of the localities south of the city centre.

In addition, data can be categorized according to the waste fraction to identify the dominant sources of different types of waste (see Figure 3). All waste fractions indicate similar patterns in terms of waste generation. Regardless of the fraction, the areas with the highest waste generation are found in the city center, with some dispersed high generation regions in the north and the south. The numerical span of the data

\footnotetext{
${ }^{1}$ Downloaded from http://geo.uni.lu/apps/fbr/index.html, courtesy of Cyrille Médard de Chardon
} 


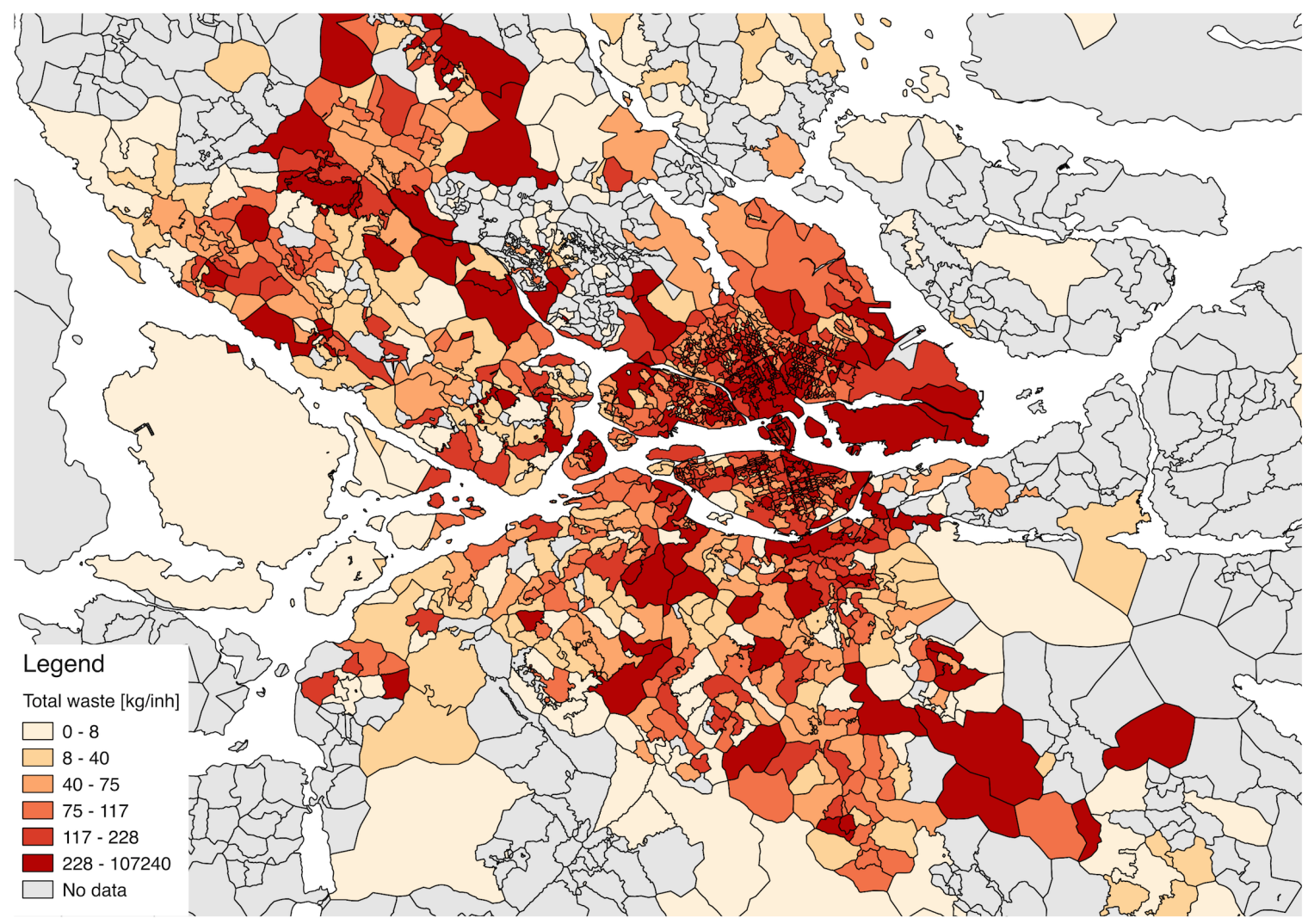

Fig. 1: Choropleth of all waste in the dataset, aggregated per zip code and normalized to population.

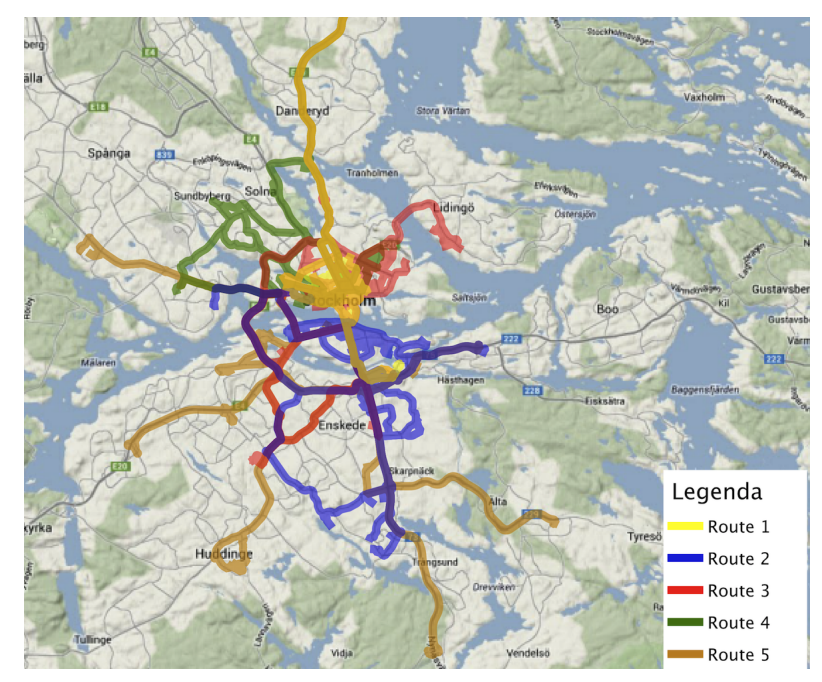

Fig. 2: Routes taken by vehicle A2.

classes in the legend indicate that bulky waste and fat waste represent the larger share, followed by mixed waste. Electronic waste only represents a minor fraction of the total waste.

\section{Efficiency Index of Vehicle Routes}

This section details the analysis of the vehicle routes across the anonymized waste management company A with two vehicles collecting bulky waste, B with four vehicles collecting mixed waste, and $\mathrm{C}$ with three vehicles.

1) Company A: The routes of vehicle A1 drove large distances between subsequent stops, with a resulting long travel time. On most of the days, two sub-routes could be discerned, one before the lunch break, one after. The calculated efficiency indices averaged at $46 \frac{\mathrm{kg}}{\mathrm{km}}$ (see Table I). From the route map it is evident that this vehicle repeatedly drives from one end of the city to the other. As a result, these routes seem to have a low efficiency index.

The other vehicle from the same company, A2, also travelled long distances across the city. The efficiency indices for these routes are in the same order of magnitude as for vehicle A1 (86 $\frac{\mathrm{kg}}{\mathrm{km}}$ ). Vehicles A1 and A2 both collected bulky waste. The routes of A2 are visualized in Figure 2

2) Company B: For this company, several vehicles were mapped and visualized for a given date, thereafter the routes for the same day, but one week later were mapped for quality control. As expected, the routes coincide at most stops.

Four vehicles are described here, the first B1, drives quite locally, in and around one suburb (Farsta); the second vehicle B2 drives longer distances. For vehicle B2, the efficiencies are in the same order of magnitude as for company A, with an average of $177 \frac{\mathrm{kg}}{\mathrm{km}}$. However, the maximum efficiency is higher with a peak of $349 \frac{\mathrm{kg}}{\mathrm{km}}$.

For the more local route (B1), the efficiencies significantly higher with $595 \frac{\mathrm{kg}}{\mathrm{km}}$ before noon, and $1054 \mathrm{~kg} / \mathrm{km}$ in the 


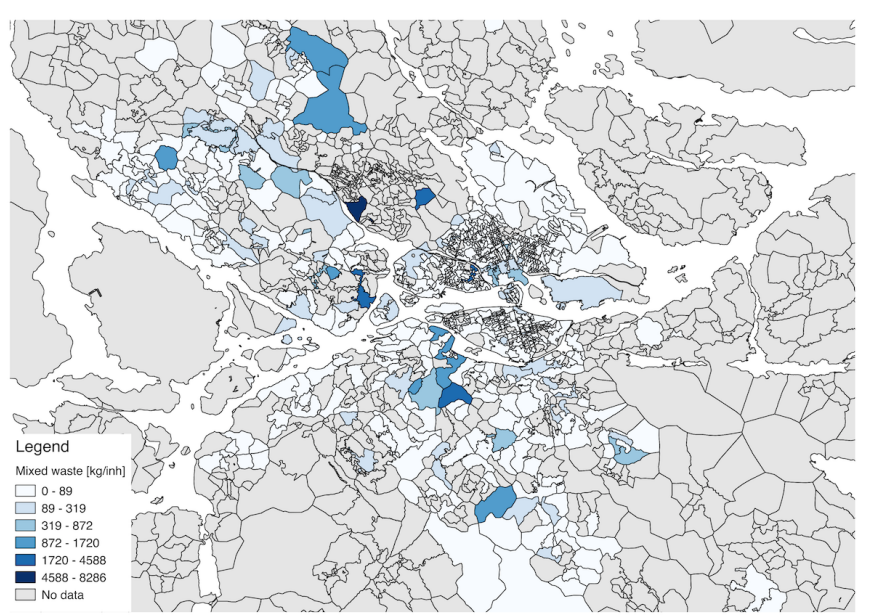

(a) Mixed Waste

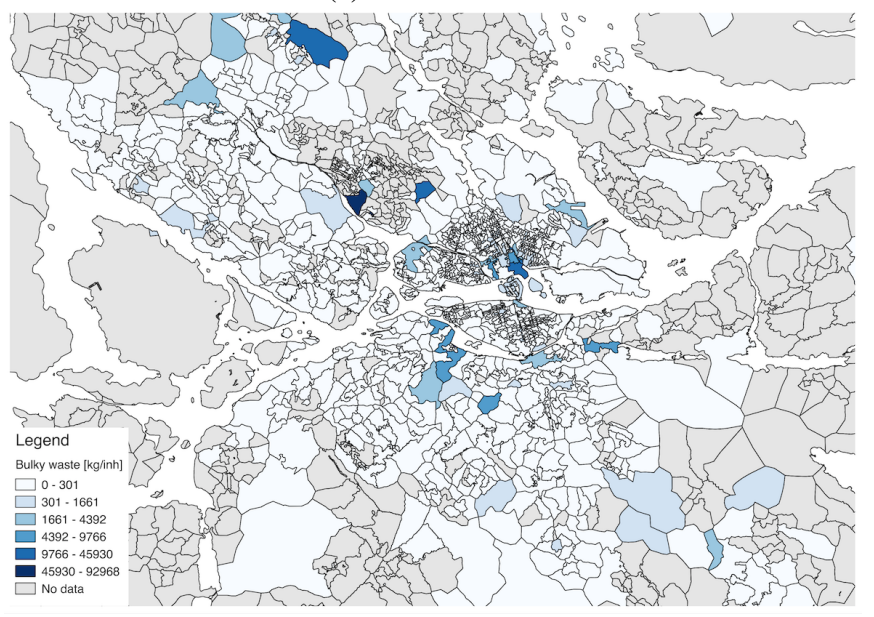

(c) Bulky Waste

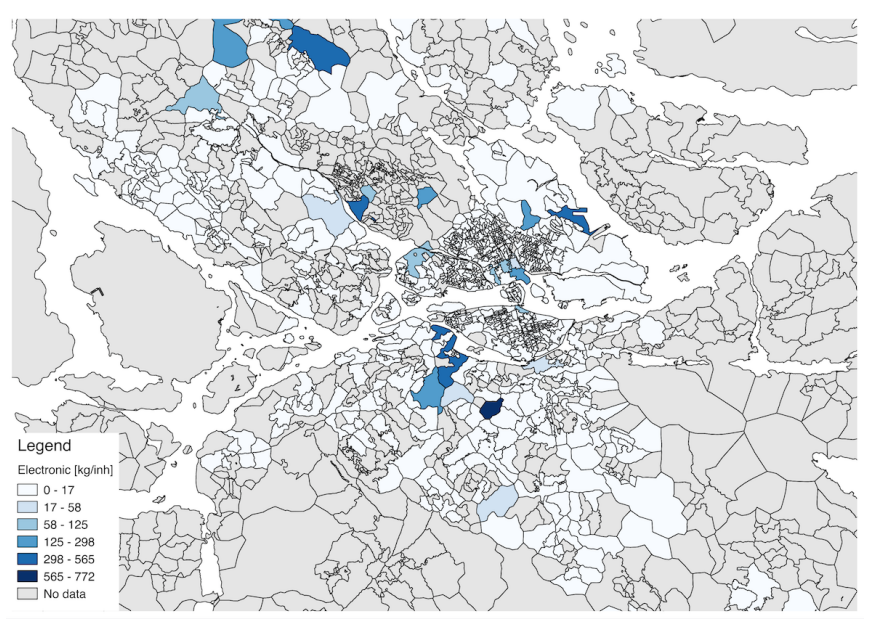

(b) Electronic Waste

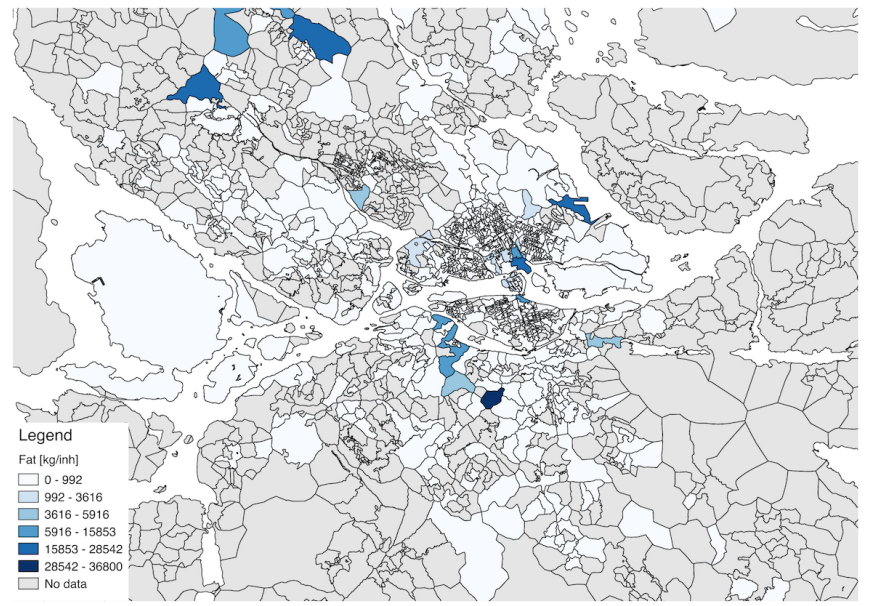

(d) Fat Waste

Fig. 3: Choropleth maps of different waste fractions

afternoon. For vehicle B3, the efficiencies are 350 and $259 \frac{\mathrm{kg}}{\mathrm{km}}$. Although these results are in no way conclusive, the vehicles of company B show that much higher efficiencies can be achieved by vehicles that have a higher spatial density of collection stops.

A significantly large amount of mixed waste is generated in weekends, which is evident by following vehicle B4 in Figure 4; this vehicle predominantly collects in Södermalm, Hammarby Sjöstad and Årsta. The routes are local and the vehicle stays in the same neighborhood in successive days. Like vehicle B1, it stays in the same neighborhood, with efficiencies of $452 \frac{\mathrm{kg}}{\mathrm{km}}$ on the first day of the week (a Monday). The following collections gradually drop in efficiency until they reach $134 \frac{\mathrm{kg}}{\mathrm{km}}$. This downward evolution suggests that collections in the same area on successive days yield a low collection efficiency. The average efficiency index for B4 is $265 \frac{\mathrm{kg}}{\mathrm{km}}$ (see Table I).

3) Company $C$ : The vehicles of company $\mathrm{C}$ collect only electronic waste and they travel large distances within the same itinerary, in a similar fashion of company A. In general

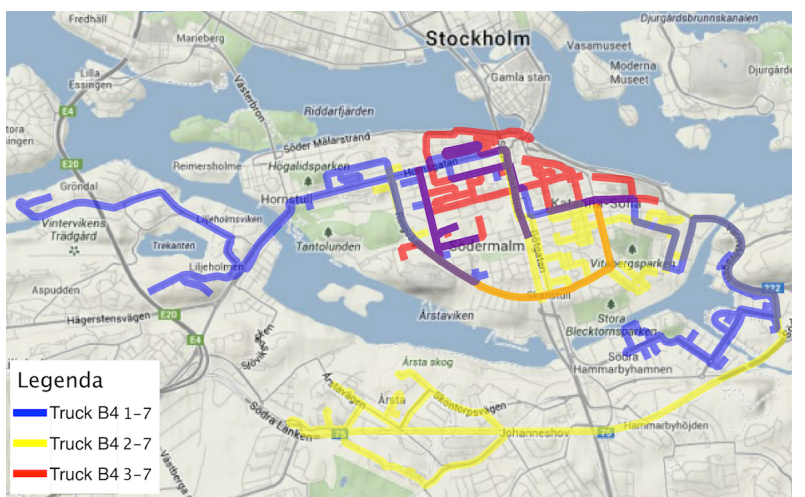

Fig. 4: Collection routes for vehicle B4 on three consecutive days.

the weight and volume of electronic waste is lower than the other waste fractions, so its efficiency index should not be compared linearly, however, its relative distribution is still relevant. The efficiencies of the sub routes average at $20 \frac{\mathrm{kg}}{\mathrm{km}}$. 


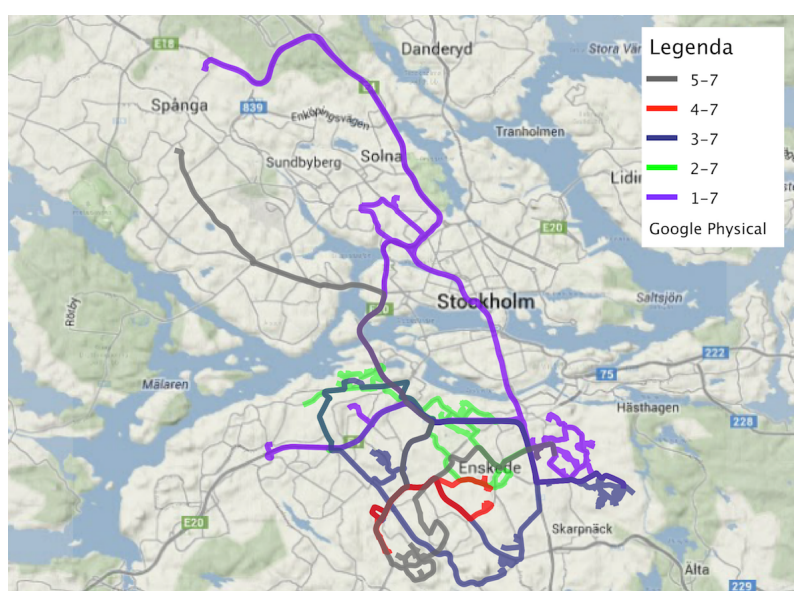

Fig. 5: Collection routes for vehicle $\mathrm{C} 2$ on multiple days.

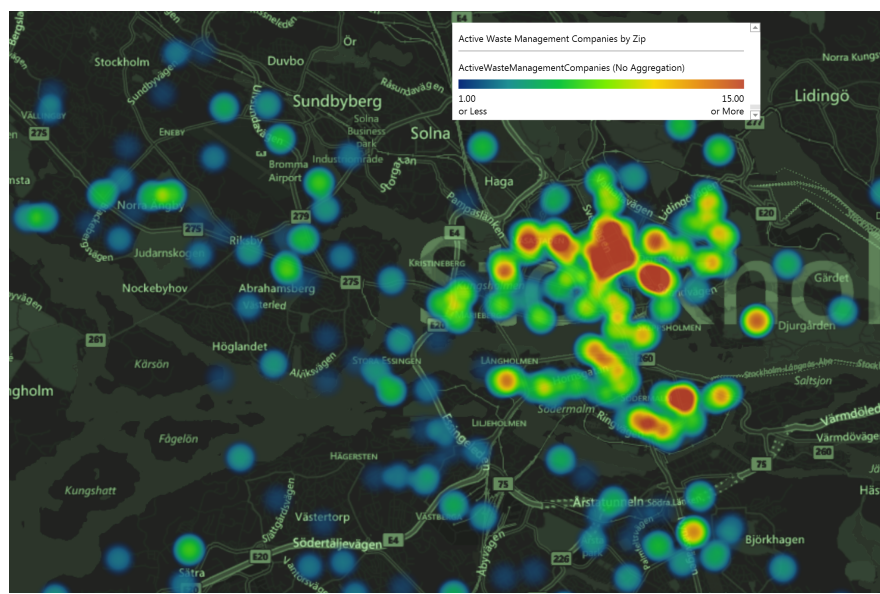

Fig. 6: Number of active waste companies per zip code area

The same vehicle $\mathrm{C} 2$ was examined on subsequent days $\mathrm{C} 2$ (see Figure 5). Figure 5 indicates that different types of routes as follows. On the 1st of July the vehicle drove a long way from north to south. On the consecutive days, the vehicle stayed in the south of Stockholm with an efficiency index maximum of $30 \frac{\mathrm{kg}}{\mathrm{km}}$.

At closer observation of the last route, the efficiency index could have been doubled if the first stop would have been left out (see leftmost point on the grey line in Figure 5).

4) Summary: Table I summarizes the initial analysis of the efficiency index of the vehicles. For comparability and to convey the spread of the indices, they were also normalized in the same table.

\section{Density of Waste Management Companies}

Based on these apparent inefficiencies, the waste company heat maps (see Figure 6) can be used to identify areas where there are a high number of companies (waste collection vehicles) within the same zip code, which might be good areas for further analysis and policy recommendation.

\section{Discussion}

In terms of a research methodology, this paper gives additional substance to the existence of the "Fourth Paradigm" of research [24] originated by the late Jim Gray. The three first research paradigms of man were empirical observation and experimentation followed by theoretical and analytical approaches, and finally computational science or simulations. The fourth paradigm is about exploring patterns, trends, and causalities through big data exploration. This study has begun the exploration of the waste data set, and still, insights remain "hidden" in the data until further explorations can be made. Within the context of a larger case study, data pertaining to energy, water, waste, and transportation was collected and could be integrated for analysis. A specific research question was not framed, beyond the objective to deliver a real-time KPI of GHGs/capita. While this waste data is currently used to deliver a part of that KPI in the Stockholm Royal Seaport, the results from this study were not foreseen. In this case, indicating the efficiency of transportation logistics of waste vehicles in the entire city, and eventually providing a number of intervention strategies can significantly decrease the city's largest source of emissions [7], namely those from the transportation sector.

In terms of implications for sustainable urban development, this study demonstrates the analytical framework with initial results from a limited number of vehicle routes. These results indicate the potential value of a complete study of all routes and vehicles to yield efficiency metrics in terms of the travelled distance per collected weight of waste. With additional information about the individual collection vehicles (fuel economy and GHG emissions), this measure could be easily transformed to $\mathrm{kg}$ of GHG per $\mathrm{kg}$ of waste.

In line with McLeod and Cherrett [19], the results from such a study could quantify the economic and environmental benefits of collection efficiency measures. Through continuous predictions of waste generation, or as in Faccio et al [22], introducing real-time weight sensing in garbage bins, collection routes could be greatly improved. Furthermore, logistic cooperation between multiple waste management companies could trigger additional collection efficiency improvements.

Despite the higher difficulty to accomplish this goal, a shared vehicle fleet as proposed in McLeod and Cherrett [19] could realise aforementioned cooperation. A parallel could be drawn with the deregulated electricity market in Sweden [25]: one organization owns and operates the fleet (analogous with the power grid), while there is a free market to offer various waste management services such as collection frequencies, recycling and processing options, etc. (in analogy with free market of energy suppliers, "renting" the common grid). By doing this, minimizing operational costs of the company that owns the waste grid, would result in minimizing (optimizing) vehicle kilometers.

Drawing on ideas from industrial symbiosis (the concept of minimizing transport and waste by transporting waste from local industries as incoming resources to other local industries) [26], another potential use of this data is to inform reuse and 
TABLE I: Summary of the studied vehicle efficiencies in $\frac{\mathrm{kg}}{\mathrm{km}}$.

\begin{tabular}{c||rr|rrrr|rrr}
\hline \multicolumn{1}{c||}{ Type } & \multicolumn{3}{c}{ Bulky } & \multicolumn{1}{c}{ Mixed } & \multicolumn{3}{c}{ Electronic } \\
\hline Vehicle & A1 & A2 & B1 & B2 & B3 & B4 & C1 & C2 & C3 \\
\hline Max & 66 & 157 & 1054 & 349 & 350 & 488 & 13 & 30 & 19 \\
Min & 28 & 49 & 594 & 82 & 259 & 134 & 10 & 7 & 19 \\
Avg & 46 & 86 & 824 & 177 & 305 & 265 & 12 & 14 & 19 \\
$\#$ & 6 & 8 & 2 & 4 & 2 & 7 & 2 & 6 & 1 \\
\hline \hline \multicolumn{1}{l||}{} & \multicolumn{10}{c}{ Normalized } \\
\hline High & $143 \%$ & $183 \%$ & $128 \%$ & $197 \%$ & $115 \%$ & $184 \%$ & $108 \%$ & $214 \%$ & $100 \%$ \\
Avg & $100 \%$ & $100 \%$ & $100 \%$ & $100 \%$ & $100 \%$ & $100 \%$ & $100 \%$ & $100 \%$ & $100 \%$ \\
Low & $61 \%$ & $57 \%$ & $72 \%$ & $46 \%$ & $85 \%$ & $51 \%$ & $83 \%$ & $50 \%$ & $100 \%$ \\
\hline
\end{tabular}

refurbishment companies about predicted high waste generation in nearby addresses. Lastly, with the aim of understanding extremes in waste generation, another potential use of this data set is to compare public facilities, such as schools and hospitals on normalized waste generation.

Since a considerable amount of resources have been used in the data curating phase, a recommendation to the City of Stockholm is to increase their data collection quality by implementing automated rules for data collection, as opposed to keeping all data collection fields as "free" text fields. And obviously, for other municipalities, this study implies the significance for them to monitor their waste collection in a similar manner. While the initial motivation for the City of Stockholm was to sense and monitor its electronic waste, since it had become a source of income to the city, the societal benefits of this data seem to surpass that financial incentive.

\section{CONCLUSION}

This study indicates that there are substantial inefficiencies in the waste management system in the City of Stockholm. A shared waste management vehicle fleet is recommended as a particularly good policy intervention. A methodology was provided to systematically quantify and map these inefficiencies. It further demonstrates that there are geotemporal patterns based on which the transportation logistics could be improved. Finally, it demonstrates the value of urban sensing, and that big data analytics should be used to inform sustainable urban development intervention measures.

\section{ACKNOWLEDGMENT}

The authors would like to thank Kenneth Carlsson for making the vast amount of data available for research; Max Jonsson and Alfred Kaiser for their valuable cooperation during the project course in which this study was initially conducted; Jan Haas for his assistance for making the zip code shapefile available and for his assistance in questions about GIS software; and Karoliina Pilli-Sihvola for her helpful comments on the first version of this paper.

\section{REFERENCES}

[1] R. T. Wright and D. Boorse, Environmental Science: Pearson New International Edition: Toward a Sustainable Future, internatio ed. United Kingdom: Pearson Education, 2013.

[2] T. Graedel and B. Allenby, Industrial Ecology and Sustainable Engineering, 2nd ed. Upper Saddle River, NJ: Prentice Hall, 2010.
[3] L. M. Hilty, W. Lohmann, and E. Huang, "Sustainability and ICTan overview of the field," POLITEIA, pp. 13-28, 2011.

[4] L. M. Hilty, Information technology and sustainability. Essays on the relationship between ICT and sustainable development. Norderstedt, Germany: Books on Demand, 2008.

[5] A. Caragliu, C. Del Bo, and P. Nijkamp, "Smart Cities in Europe," Journal of Urban Technology, vol. 18, no. 2, pp. 65-82, Apr. 2011. [Online]. Available: http://www.tandfonline.com/doi/abs/10.1080/ 10630732.2011 .601117

[6] Directorate-general for Internal Policies, "Mapping Smart Cities in the EU," European Parliament, Brussels, Tech. Rep., 2014

[7] S. Johansson, H. Shahrokni, A. R. Kristinsdóttir, and N. Brandt, "Creating a Climate Positive Urban District A Case Study of Stockholm Royal Seaport," Forthcoming, Energy Policy, 2014.

[8] J. Eliasson, L. Hultkrantz, L. Nerhagen, and L. S. Rosquist, "The Stockholm congestion charging trial 2006: Overview of effects," Transportation Research Part A: Policy and Practice, vol. 43, no. 3, pp. 240-250, 2009. [Online]. Available: http: //www.sciencedirect.com/science/article/pii/S0965856408001572

[9] A. Guhr, "The potentials of information and communications technology to improve waste management in Stockholm," 2014.

[10] G. Bell, T. Hey, and A. Szalay, "Beyond the data deluge," Science, vol. 323, no. March (5919), pp. 1297-1298, 2009. [Online]. Available: http://www.cloudinnovation.com.au/Bell $\backslash$ Hey $\backslash$ Szalay $\backslash$ Science $\backslash \_$March $\backslash \_2009 . p d f$

[11] T. Kindberg, M. Chalmers, and E. Paulos, "Urban Computing," IEEE Pervasive Computing, vol. 6, no. 3, pp. 18-20, 2007.

[12] W. Z. Hirsch, "Cost Functions of an Urban Government Service: Refuse Collection," The Review of Economics and Statistics, vol. 47, no. 1, pp. 87-92, 1965

[13] N. Bosch, F. Pedraja, and J. Suárez-Pandiello, "Measuring the efficiency of Spanish municipal refuse collection services," Local Government Studies, vol. 26, no. 3, pp. 71-90, Sep. 2000. [Online]. Available: http://www.tandfonline.com/doi/abs/10.1080/03003930008434000

[14] E. Dijkgraaf and R. H. J. M. Gradus, "Cost Savings of Contracting Out Refuse Collection," Empirica, vol. 30, no. 2, pp. 149-161, 2003.

[15] N. Rogge and S. De Jaeger, "Measuring and explaining the cost efficiency of municipal solid waste collection and processing services," Omega, vol. 41, no. 4, pp. 653-664, Aug. 2013. [Online]. Available: http://linkinghub.elsevier.com/retrieve/pii/S0305048312001867

[16] S. De Jaeger, J. Eyckmans, N. Rogge, and T. Van Puyenbroeck, "Wasteful waste-reducing policies? The impact of waste reduction policy instruments on collection and processing costs of municipal solid waste." Waste management (New York, N.Y.), vol. 31, no. 7, pp. 1429-40, Jul. 2011. [Online]. Available: http://www.ncbi.nlm.nih.gov/ pubmed/21429732

[17] I. Garcia-Sanchez, "The performance of Spanish solid waste collection," Waste Management \& Research, vol. 26, no. 4, pp. 327-336, Aug. 2008. [Online]. Available: http://wmr.sagepub.com/cgi/doi/10.1177/ $0734242 X 07081486$

[18] B.-I. Kim, S. Kim, and S. Sahoo, "Waste collection vehicle routing problem with time windows," Computers \& Operations Research, vol. 33, no. 12, pp. 3624-3642, Dec. 2006. [Online]. Available: http://linkinghub.elsevier.com/retrieve/pii/S0305054805001322

[19] F. McLeod and T. Cherrett, "Quantifying the transport impacts of domestic waste collection strategies." Waste management (New York, N.Y.), vol. 28, no. 11, pp. 2271-8, Nov. 2008. [Online]. Available: http://www.ncbi.nlm.nih.gov/pubmed/18083362 
[20] J. Wy, B.-I. Kim, and S. Kim, "The rollonrolloff waste collection vehicle routing problem with time windows," European Journal of Operational Research, vol. 224, no. 3, pp. 466-476, Feb. 2013. [Online]. Available: http://linkinghub.elsevier.com/retrieve/pii/S0377221712006649

[21] K. Buhrkal, A. Larsen, and S. Ropke, "The Waste Collection Vehicle Routing Problem with Time Windows in a City Logistics Context," Procedia - Social and Behavioral Sciences, vol. 39, pp. 241-254, Jan. 2012. [Online]. Available: http://linkinghub.elsevier.com/retrieve/ $\mathrm{pii} / \mathrm{S} 1877042812005721$

[22] M. Faccio, A. Persona, and G. Zanin, "Waste collection multi objective model with real time traceability data." Waste management (New York, N.Y.), vol. 31, no. 12, pp. 2391-405, Dec. 2011. [Online]. Available: http://www.ncbi.nlm.nih.gov/pubmed/21821406
[23] G. F. Jenks and F. C. Caspall, "Error on choroplethic maps: definition, measurement, reduction," Annals of the Association of American Geographers, vol. 61, no. 2, pp. 217-244, 1971. [Online]. Available: http://www.tandfonline.com/doi/abs/10.1111/ j.1467-8306.1971.tb00779.x

[24] T. Hey, S. Tansley, and K. Tolle, Eds., The Fourth Paradigm: Dataintesive scientific discovery, redmond, w ed. Microsoft Research, 2009.

[25] J. Ahlström, "Den avreglerade elmarknaden," 2005.

[26] G. Aid, N. Brandt, M. Lisenkova, and N. Smedberg, "Looplocal: a Heuristic Visualization Tool for the Strategic Facilitation of Industrial Symbiosis," Greening of Industry ..., 2012. [Online]. Available: http://www.diva-portal.org/smash/record.jsf?pid=diva2:622144 